\title{
Diagnostic criteria for exercise dependence in women
}

\author{
D J Bamber, I M Cockerill, S Rodgers, D Carroll
}

Br J Sports Med 2003;37:393-400

See end of article for authors' affiliations .....................

Correspondence to: Dr Bamber, University of Cambridge, Douglas House, 18b Trumpington

Road, Cambridge CB4 6ZG, UK; djb69@cam.ac.uk

Accepted

20 October 2002
Objective: To formulate diagnostic criteria for exercise dependence.

Method: Fifty six adult female exercisers were interviewed about their exercise behaviour and attitudes. The eating disorders examination, a semistructured clinical interview, was used to diagnose eating disorders. Interviews were taped, transcribed verbatim, and analysed from a social constructionist perspective using QSR NUD*IST. Participants also completed the exercise dependence questionnaire.

Results: Two diagnostic criteria emerged from analysis of the interview data: impaired functioning and withdrawal. Impaired functioning was manifest in four areas: psychological, social and occupational, physical, and behavioural. Impairment in at least two areas was considered necessary for diagnosis. Withdrawal was evident as either an adverse reaction to the interruption of exercise or unsuccessful attempts at exercise control. Either sufficed for diagnosis. The absence or presence of an eating disorder was used to distinguish between primary and secondary exercise dependence. Ten women met these criteria for exercise dependence. All 10 also exhibited eating disorders and, accordingly, should be regarded as showing secondary, rather than primary, exercise dependence. Exercise dependent women had significantly higher scores on the exercise dependence questionnaire than non-dependent women.

Conclusion: These new diagnostic criteria should now be adopted and explored further, particularly among men and individuals with possible primary exercise dependence.
E xercise dependence is now the preferred term for a seemingly unhealthy preoccupation with exercising. As eating disorders commonly co-occur with problematic exercise, ${ }^{1-3}$ the terms primary and secondary exercise dependence have been coined to differentiate between excessive exercising as an independent pathology and as an associated feature of an underlying eating disorder. ${ }^{4}$ Irrespective of its status as a primary or secondary condition, there have now been various attempts to characterise and measure exercise dependence. Some researchers have operationalised exercise dependence in terms of the frequency and/or amount of exer-

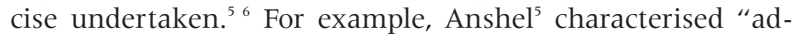
dicted runners" as "Persons engaging in structured and nonstructured activity programs at the (health) club at least 5 days per week for a minimum of 15 hours per week over the past 20 weeks". The main problem with this approach is that it fails to distinguish between committed and problematic exercisers. By focusing only on behavioural criteria, critical attitudinal, emotional, and motivational factors are neglected.

Although not ignoring exercise behaviour, others have emphasised the psychological characteristics of dependence, such as experience of withdrawal symptoms, including anxiety or depression when unable to exercise, as indicative of exercise dependence. ${ }^{48}$ The latter approach has largely informed the numerous questionnaires that have been developed to measure exercise dependence. For example, the exercise dependence questionnaire ${ }^{9}$ and the obligatory exercise questionnaire $^{10}$ attempt to measure such attributes as withdrawal symptoms, stereotyped behaviour, and interference with social functioning.

However, there are a number of problems with the questionnaire approach at this stage in our understanding of exercise dependence. Firstly, in the absence of agreed and validated criteria for exercise dependence, the choice of items explored on questionnaires must, to an extent, be arbitrary.

Secondly, appropriate cut off points remain to be determined. For example, in a recent study using the exercise dependence questionnaire, the female participants were con- sidered to be exercise dependent if their scores were $\geqslant 116 .{ }^{11}$ As items are scored on a 1-7 point Likert scale, this cut off represents an average cut off score of at least 4 on each of the 29 items - that is, they did not disagree, on average, with such statements as "The rest of my life has to fit around my exercise" and "If I cannot exercise I feel irritable." However, in the absence of an eating disorder, female exercisers meeting this criterion did not exhibit the sorts of personality profiles, high levels of neuroticism, addictiveness, and impulsivity and the levels of psychological distress that are characteristic of other dependencies. ${ }^{12-14}$ Thirdly, existing exercise dependence questionnaires do not differentiate between primary exercise dependence and problematic exercise as an associated characteristic of an eating disorder. In the study by Bamber and colleagues, ${ }^{11}$ female exercisers who met the criterion described above, but also showed evidence of an eating disorder on the eating disorders examination questionnaire, ${ }^{15}$ displayed the expected morbid personality characteristics and high levels of psychological distress.

As yet, there has only been one attempt to develop proper diagnostic criteria for exercise dependence. Based on clinical experience, Veale ${ }^{4}$ produced a set of diagnostic criteria for primary and secondary exercise dependence (table 1) analogous to those used for diagnosing other dependence syndromes. ${ }^{16}$ However, there has been insufficient evidence to support the existence of primary exercise dependence and, accordingly, to convince the American Psychiatric Association that exercise dependence should be recognised as an independent clinical disorder.

Clearly, there is a need to strengthen the empirical base of exercise dependence. A qualitative approach may be better suited than a quantitative one for exploring potential diagnostic criteria for exercise dependence, as qualitative

Abbreviations: $E D E$, eating disorders examination; EXDI, exercise dependence interview; $E D Q$, exercise dependence questionnaire 
Table 1 Proposed diagnostic criteria for primary and secondary exercise dependence ${ }^{4,8}$

Primary exercise dependence

1. Preoccupation with exercise which has become stereotyped and routine

2. Significant withdrawal symptoms in the absence of exercise (e.g. mood swings, irritability, insomnia)

3. The preoccupation causes clinically significant distress or impairment in their physical, social, occupational, or other important areas of functioning

4. The preoccupation with exercise is not better accounted for by another mental disorder (e.g. as a means of losing weight or controlling calorie intake as in an eating disorder)

Secondary exercise dependence

1. Narrowing of repertoire leading to stereotyped pattern of exercise with a regular schedule once or more daily

2. Salience with the individual giving increasing priority over other activities to maintaining the pattern of exercise

3. Increased tolerance to the amount of exercise performed over the years

4. Withdrawal symptoms related to disorder of mood after cessation of exercise schedule

5. Relief or avoidance of withdrawal symptoms by further exercise

6. Subjective awareness of a compulsion to exercise

7. Rapid reinstatement of the previous pattern of exercise and withdrawal symptoms after a period of abstinence

Associated features

1. Either the individual continues to exercise despite a serious physical disorder known to be caused, aggravated, or prolonged by exercise and is advised as such by a health professional, or the individual has arguments or difficulties with his/her partner, family, friends, or occupation

2. Self inflicted loss of weight by dieting as a means towards improving performance

methods can provide richer accounts of individual experience. As the nature of exercise dependence remains to be determined, a wholly quantitative approach may be premature. Indeed, the general reliance on quantitative methods may well be impeding the further development of diagnostic criteria and, accordingly, our general understanding of exercise dependence. To date, the application of qualitative methods in this context has been limited to a few case studies. ${ }^{17-20}$ The present study applied a rigorous and systematic qualitative approach with a view to extracting diagnostic criteria for primary and secondary exercise dependence. Given Veale's preliminary exploration of diagnostic criteria and the expanding literature on exercise dependence, an approach based on a social constructionist mode of grounded theory was adopted. ${ }^{21}$ This approach encourages new ideas to emerge while acknowledging and challenging existing ones ${ }^{22}$ and was therefore deemed best suited to current research needs.

\section{METHOD \\ Participants}

Interviews were conducted with 56 adult female exercisers recruited from a variety of sources, including: aerobics classes; sports centres; athletics and running clubs; the Eating Disorders Association; a private eating disorder clinic; the readership of Athletics weekly and Runner's world magazines; the United Kingdom Athletics Organisation. Mean (SD) age was 28.90 (8.36) years, mean (SD) objectively measured body mass index was 22.78 (3.78), and mean (SD) age at menarche was 13.59 (1.69) years. Skinfold thicknesses were taken to derive estimated mean (SD) percentage body fat of $21.65(7.82) .^{23}$ Participants were recruited through mail shots, magazine adverts, or by being given a questionnaire at an exercise class. They were invited to enter a "Lifestyle study", and participation was voluntary. Most of the participants were white (89\%); $5 \%$ identified themselves as Afro-Caribbean, $2 \%$ as Asian, and $4 \%$ as mixed ethnicity. Most ( $80 \%)$ were single.

\section{Interview schedule}

The two part semistructured interview, comprising the eating disorders examination (EDE) ${ }^{24}$ and the exercise dependence interview (EXDI), has been described in detail elsewhere. ${ }^{11}$ To improve accuracy and recall, interviews began with a detailed discussion of events over the preceding three months. Participants made notes on a calendar, which was used throughout the interview along with their personal diaries. Detailed probing and use of temporal anchors facilitated accurate recall of more distant past events. A comprehensive debriefing format was used for any participants who expressed disordered eating attitudes and behaviours, and all participants were given the opportunity to ask any questions about the research. Order of administration of the EDE and EXDI was counterbalanced, and all interviews were conducted by the first author who was trained in the administration of the $\mathrm{EDE}^{24}$ and had completed a one year training course in counselling skills and theory. Interviews were tape recorded and lasted one to three hours. Full written informed consent was obtained before each interview. Finally, before the interview, participants completed the exercise dependence questionnaire (EDQ). ${ }^{9}$

\section{Data preparation and analysis}

The procedures used for analysis of the qualitative data have been detailed previously. ${ }^{11}$ Briefly, all interviews were transcribed verbatim, participants' responses to the EDE were coded, and eating disorder diagnoses were made. ${ }^{24}$ All subjects' names were changed to maintain confidentiality. An inter-rater reliability study was carried out, whereby the third author, a chartered clinical psychologist, assessed 25 interviews for eating disorders and possible exercise dependence. Her assessments agreed $100 \%$ with those of the first author. A precis of each interview was made, and any new consistent themes were noted ${ }^{25}$ and added to the summary sheet. Interview transcripts, post-interview journal entries, and summary sheets were imported into the QSR NUD*IST 4.0 (nonnumerical unstructured data indexing searching and theorising) software package. ${ }^{26}$ Interview transcripts were divided into "text units" - lines of text — which were coded and placed into categories in the index system, a framework of nodes for text units that referred to themes-for example, withdrawal. This process continued until no new themes emerged, and theoretical saturation was reached. Again, the third author provided a second opinion at each stage of the analysis. Consensus was reached about the nature and operational definitions of the themes and their position in the index system. An audit trail of theoretical memos was stored within NUD*IST and findings were verified by searching for negative cases. ${ }^{27}$

\section{Diagnoses and quantitative assessment}

A second stage of the study involved re-examining the responses of all 56 interviewees using the diagnostic criteria derived from the narratives to characterise participants as primary or secondary exercise dependent. These diagnoses were compared with participants' scores on the EDQ. 
Table 2 Emergent themes relating to diagnostic criteria for exercise dependence

\begin{tabular}{|c|c|c|c|}
\hline Raw data - examples & First order themes & Second order themes & General dimension \\
\hline $\begin{array}{l}\text { "I have to think that people have to sit down } \\
\text { in an office day after day . . it's like a power } \\
\text { of struggle and my brain's never quiet, trying } \\
\text { to reason..." }\end{array}$ & $\begin{array}{l}\text { Intrusive thoughts/ruminations } \\
\text { Salience of thoughts about exercising } \\
\text { Anxiety, depression } \\
\text { Anger, frustration, agitation, irritability } \\
\text { Guilt, insomnia, lethargy, loss of motivation, } \\
\text { Impaired concentration, feel confined }\end{array}$ & Psychological & Impaired functioning \\
\hline $\begin{array}{l}\text { "It's exercise or nothing" } \\
\text { "I'd always turn something down if it was } \\
\text { going to interfere with my routine" } \\
\text { "My exercise is my social life, I don't have a } \\
\text { social life outside that" }\end{array}$ & $\begin{array}{l}\text { Salience of exercising above other activities } \\
\text { Social isolation/withdrawal } \\
\text { Inability to work, late for work, impaired } \\
\text { concentration/functioning at work } \\
\text { Irritability with colleagues, partners, friends, } \\
\text { family. } \\
\text { Conflict in relationships }\end{array}$ & Social and occupational & \\
\hline $\begin{array}{l}\text { "I went to the doctor and he said ... you } \\
\text { have got to slow down, don't do so much } \\
\text { exercise, erm, but I didn't" }\end{array}$ & $\begin{array}{l}\text { Medically contraindicated exercising } \\
\text { Injury } \\
\text { Illness } \\
\text { Fatigue }\end{array}$ & Physical & \\
\hline $\begin{array}{l}\text { "I go (walking) at half past } 7 \text { and then I go at } \\
\text { half past } 10 \text { and then I go at half past } 1 \text { and } \\
\text { then I go at half past } 4 \text {, so structured" } \\
\text { "I sometimes really push myself. . . because I } \\
\text { am bad, because I have done something that } \\
\text { I shouldn't have" }\end{array}$ & $\begin{array}{l}\text { Stereotyped and inflexible behaviour } \\
\text { Self harm/punishing }\end{array}$ & Behavioural & \\
\hline $\begin{array}{l}\text { "I wouldn't think I deserved the food" } \\
\text { "I should be feeling very depressed and } \\
\text { angry and anxious...I would be ready to be } \\
\text { hospitalised" }\end{array}$ & $\begin{array}{l}\text { Change in eating behaviour/cognitions (e.g. } \\
\text { bingeing, dietary restriction, fear eating) } \\
\text { Fear weight gain } \\
\text { Increase alcohol/substance use } \\
\text { Severe anxiety, depression, loss motivation. }\end{array}$ & $\begin{array}{l}\text { Adverse response to change } \\
\text { in/interruption of exercise } \\
\text { habits }\end{array}$ & Withdrawal \\
\hline $\begin{array}{l}\text { "I'd love to lie on the settee and watch video } \\
\text { after video" } \\
\text { "It (exercising) speeded up again and now } \\
\text { I'm trying to cut down" }\end{array}$ & $\begin{array}{l}\text { Fantasies about not exercising } \\
\text { Desire to cut down } \\
\text { Inability to cut down } \\
\text { Feeling exercising is out of own control }\end{array}$ & $\begin{array}{l}\text { Persistent desire and/or } \\
\text { unsuccessful attempts to } \\
\text { control/reduce exercise }\end{array}$ & \\
\hline $\begin{array}{l}\text { "The more I do it the more it seems that I need } \\
\text { to do it" } \\
\text { "It has a tendency to creep up" } \\
\text { "If I start doing the exercising . . I will start } \\
\text { doing more and more of it" }\end{array}$ & $\begin{array}{l}\text { Increased volume exercise (frequency, } \\
\text { intensity, duration) } \\
\text { Decreased exercise } \\
\text { Fear of addiction } \\
\text { Performance/non-performance related }\end{array}$ & Tolerance & Associated features \\
\hline $\begin{array}{l}\text { " } 4 \text { and a half to } 6 \text { hours per day plus (horse) } \\
\text { riding" } \\
\text { "There aren't many people in my front room } \\
\text { at } 5 \text { am" }\end{array}$ & $\begin{array}{l}\text { High volume } \\
\text { Mode, frequency, duration, intensity } \\
\text { Solitary exercising }\end{array}$ & Exercise behaviour & \\
\hline $\begin{array}{l}\text { "I probably underestimate it" } \\
\text { ". . . a bit economical with the truth . . and I } \\
\text { don't tell then about the hill profiles and } \\
\text { speed" }\end{array}$ & $\begin{array}{l}\text { Lying about exercising } \\
\text { Exercising in secret } \\
\text { Denial - self/others } \\
\text { Insight/awareness of problem }\end{array}$ & Deception/insight & \\
\hline $\begin{array}{l}\text { "my main reason for exercising is to be good, } \\
\text { but I know that to be good I also need to be } \\
\text { thin". } \\
\text { "control, control full stop." } \\
\text { "because I have to" }\end{array}$ & $\begin{array}{l}\text { Performance } \\
\text { Weight/shape control } \\
\text { Mood, sleep } \\
\text { Break from work } \\
\text { Physical health } \\
\text { Social } \\
\text { Need to be active } \\
\text { Feeling in control } \\
\text { Self punishment } \\
\text { Regulation emotions } \\
\text { Physical self efficacy } \\
\text { Sense of compulsion }\end{array}$ & Exercise motives & \\
\hline $\begin{array}{l}\text { Responses to each of the } 36 \text { EDE items } \\
\text { "I always feel guilty after eating" } \\
\text { "I feel fat and ugly and I hate myself at the } \\
\text { moment" } \\
\text { "It (weight) makes me feel awful, it just makes } \\
\text { me feel really bad about myself." }\end{array}$ & $\begin{array}{l}\text { EDE interview questions } \\
\text { e.g. "Have you felt guilty about eating?" } \\
\text { "How have you been feeling about your } \\
\text { weight?" }\end{array}$ & $\begin{array}{l}\text { Clinical eating disorder } \\
\text { Disordered eating } \\
\text { No eating disorder }\end{array}$ & $\begin{array}{l}\text { Presence of an eating } \\
\text { disorder (primary or } \\
\text { secondary dependence) }\end{array}$ \\
\hline
\end{tabular}

EDE, Eating disordres examination.

\section{RESULTS}

Table 2 summarises the findings from the analyses; examples of raw data, higher order themes, and general dimensions are detailed. The four general dimensions pertinent to the diagnosis of exercise dependence that emerged were: impaired functioning, withdrawal, presence of an eating disorder, associated features.

\section{Impaired functioning}

This dimension referred to significant dysfunction in four areas: $(a)$ psychological; $(b)$ social and occupational; $(c)$ physical; (d) behavioural. Assessment of significance of any functional impairment was based on the evidence provided by participants' narratives and was confirmed by the third author's clinical opinion. The following interchange shows impaired psychological functioning manifested as intrusive thoughts about exercise:

DB: "Over the past four weeks, have you spent much time thinking about exercising?"

Peta: "Oh yes, I plan it every night, I plan it in my head when I get up every morning."

DB: "Has thinking about exercising interfered with your ability to concentrate in the same way that food has?"

Peta: "Yes, yes."

DB: "Have you had to force yourself back to concentrating?" Peta: "Yes, I am having to do it now, yes." 
Millie described how she experienced intrusive thoughts about exercising:

"It interferes with my concentration for two reasons, one, because I dread it, because I hate those aerobics classes . . . so I think about it, like, 'Oh no I really don't want to do this', but I feel I must, and then when I don't have the opportunity, that makes me think about it ..."

Annie's exercise was the only activity in her life, "It's exercise or nothing." She had given up the occupation for which she was trained to accommodate exercise. Further, when asked if her exercising interfered with her social life she replied, "I don't have a social life anymore ... I don't have the energy for a social life." As Annie's exercise regimen involved a 5 am start, evening socialising was out of the question. For others, their exercising threatened intimate relationships. As Jessica described:

"It used to cause so many arguments because, erm, all I wanted to do was exercise, I wasn't interested in anything else at all, I had even got my son, Grant, but everything had to come second to that, it didn't matter what, as long as I could get my exercise, it was like my fix. I had to get my fix otherwise I was in a foul mood. I felt totally guilty if I missed a lesson, it was mainly, like I say, conflicts between me and my partner, just caused so many arguments."

Unlike non-dependent exercisers, who rarely reported difficulties taking necessary rest when ill or injured, dependent exercisers like Annie would exercise even when medically contraindicated:

"I have knackered my knee joints and I have got arthritis in my knees and ankles from too much exercise, and I have crumbling hip joints from overexercise, so I know I have got permanent knee and shin injuries that I have given myself from overexercise, but I still continue to do it."

Annie even reported having continued to exercise after being thrown off a horse, admitting: "Whenever I am told to rest I always ignore it. If I broke a leg I would find something to do."

Although regular exercising was common to many participants, particularly those involved in competitive sport, dependent exercisers exhibited unusually stereotyped and inflexible behaviour around exercise. For example, Samantha described her exercising as: "Very very structured, it has to be, I like it to be a routine." In contrast, Angie had a much more relaxed attitude towards her exercising:

"From week to week it's very variable but on average I try to aim for roughly the same kind of things each week, but if I can't make a class and the weather's nice I'll go out for a run instead, I'm not that, my life is not governed to the point where the world stops to get to aerobics for half past five, if I can't go I can't go, I'll do something else, or l'll go home and do nothing occasionally."

\section{Withdrawal}

Issues related to withdrawal emerged as two themes. The first was "clinically significant adverse response to a change in or interruption of exercise habits". This was often manifest as anxiety, depression, anger, or guilt. In contrast, nondependent exercisers did not have a severe reaction to not being able to exercise. For example, when Barbara had to miss her swim she coped: "I felt disappointed but I cheered myself up, I bought myself a new swimming costume. You see, it wasn't earth shattering, it would have been nice, I had planned to go, but it didn't work out." Peta, on the other hand, displayed a marked psychological reaction to missing her swim:

"I was mad at myself, I felt really angry, I couldn't concentrate on anything and I felt moody and aggressive. I was really sarcastic with my husband and I felt like a big fat blob. Oh it was a dreadful day, I just felt so agitated and so out of control. It was a rotten time, and the other time when I couldn't I felt angry at that person, I felt angry at everybody because I couldn't go and get my hour in the gym or a swim and just like, less interested, just not interested in anything."

Reported physical symptoms included headaches and insomnia, and common social responses included putting exercising before socialising. Millie's account of a day out was illustrative:

"I remember one day when I drove my mum over to my sister's and she's there with a newborn baby, obviously struggling, and we were supposed to be there to help, but all I could think about was, "I have got to get out and go for a walk" ... we went for this walk and I wanted to leave then and there and go for my walk ... they wanted me to go and sit down and have a cup of tea and chat . . . and all I wanted was to go for a walk, I wasn't thinking about the baby. . . I brought them back and dumped them . . and went off and had my walk anyway."

Laura explained how her need to exercise was a source of conflict in social situations; she gave an example: "Trying to walk to places when other people are trying to go on a bus or something." In contrast, Joan, who was not exercise dependent, said "Exercising doesn't tend to win out [over other activities] these days."

Behavioural responses to not being able to exercise included binge eating or increased rigidity around eating. Meg was one of many who experienced a seeming paradoxical response to not exercising, "If I haven't exercised I tend to eat far more junk stuff and I am at far greater risk of bingeing". Others reacted with extreme dietary restraint, Joan explained "I would stick to very familiar, tried and tested foods...a very narrow range...would be very restrictive ...". Jenny, on the other hand, felt that she would have to continually weigh herself to determine how much she should be eating.

The second theme under the general dimension of withdrawal was "evidence of a persistent desire and/or unsuccessful efforts to control or reduce exercise." Some participants fantasised about not having to exercise. Peta described the conflict between feeling the need to continue exercising and inner desire for some respite:

". . . there's a part of me deep down that would like a rest, you know, I love it, you know when I've got flu, oh it's great to be able to sit down on the settee, because I've got flu, but I'm still agitated at myself, it's a terrible, terrible conflict . . . I'd love someone to say 'You have to lie down on the settee all day', I'd love to lie down on the settee and watch video after video ..."

Annie expressed similar fantasies about not having to exercise: "I think it's a dream that I would love to be able to do at one point in the future but at the moment I would not be able to, no way." She also reported failed attempts to reduce her exercising to a more reasonable level: "I try to cut down but I know that I won't". 
Table 3 New diagnostic criteria for secondary exercise dependence

The following three criteria are necessary for a diagnosis of secondary exercise dependence: 1. Impaired functioning*

The individual shows evidence of impaired functioning in at least two of the following areas:

(a) Psychological-e.g. ruminations or intrusive thoughts about exercise, salience of thoughts about exercise, anxiety, or depression

(b) Social and occupational-e.g. salience of exercising above all social activities, inability to work

(c) Physical-e.g. exercising causes or aggravates health or injury yet continues to exercise when medically contraindicated

(d) Behavioural-e.g. stereotyped and inflexible behaviour

2. Withdrawal

The individual shows evidence of one or more of the following:

(a) Clinically significant adverse response to a change or interruption of exercise habits. Response may be physical, psychological, social, or behavioural,

e.g. severe anxiety or depression, social withdrawal, self harmt

(b) Persistent desire and/or unsuccessful efforts to control or reduce exercise

3. Presence of an eating disorder $\ddagger$

Associated features

The following features are indicative but not definitive:

(i) Tolerance-i.e. increasing volumes of exercising required

(ii) High volumes of exercising and/or exercising at least once daily

(iii) Solitary exercising

(iv) Deception-e.g. lying about exercise volume, exercising in secret

(v) Insight-e.g. denial that exercising is a problem

*Exercise is unreasonably salient and/or stereotyped even when considered in appropriate context-e.g. individual is a competitive athlete.

†If individual had not abstained from exercise, or would refuse to do so, rate withdrawal according to anticipated response.

$\ddagger$ For a diagnosis of primary exercise dependence, all criteria may be the same as for secondary exercise dependence except for the absence, rather than presence, of an eating disorder.

\section{Presence of an eating disorder}

The EDE identified 18 participants as having an eating disorder at the time of interview. A further nine participants showed disordered eating - that is, problematic eating behaviour and attitudes that did not currently warrant a clinical diagnosis

\section{Associated features}

Additional themes (table 2) that emerged from the narratives included: tolerance, manifested as a progressive increase in exercise volume; high volumes of exercising and/or daily exercising; solitary exercising; deception, for example, lying about exercising; exercising driven predominantly by the desire to control weight, shape, or body composition.

\section{Diagnostic criteria}

Table 3 summarises the diagnostic criteria derived from the analysis of these exercisers' narratives. Associated features were considered indicative but not definitive of exercise dependence. Impaired functioning and withdrawal were regarded by the clinical psychologist on the team (SR) as highly problematic and matters of definite clinical concern. After discussions of the narratives and the emergent themes, there was a consensus between the first author and the clinician that impairments in two or more of the four areas of functioning and withdrawal in either or both of its manifestations strongly intimated pathology and, accordingly, provided appropriate diagnostic criteria for exercise dependence. The presence of an eating disorder qualifies exercise dependence as secondary. The same diagnostic criteria, but in the absence of an eating disorder, are likely to qualify exercise dependence as primary, although evidence from individuals who exhibit possible primary exercise dependence needs to be examined systematically before definitive criteria for primary exercise dependence can be offered.

\section{Diagnoses}

When participants' responses were judged against these diagnostic criteria, 10 met the criteria for exercise dependencethat is, they showed impaired functioning in at least two areas and evidence of withdrawal. A further four showed disordered exercising - that is, problematic exercising that failed to meet fully the criteria. The remaining 42 showed symptoms of neither exercise dependence nor disordered exercising. Of the 10 exercise dependent women, all showed evidence of an eating disorder, and, as such, were best regarded as displaying secondary rather than primary exercise dependence. In addition, disordered exercising was only present when accompanied by symptoms of an eating disorder. Of the eight participants diagnosed with an eating disorder but no exercise dependence, one provided evidence of disordered exercising. Similarly, three of the nine participants who showed problematic eating behaviour and attitudes that fell short of a clinical eating disorder, also showed disordered exercising.

\section{Quantitative findings}

The mean (SD) score on the EDQ of the 10 participants who met our diagnostic criteria for exercise dependence was 136.3 (19.30). The mean (SD) score on the EDQ for the four people who showed disordered exercising that fell short of exercise dependence was 115.3 (22.87). The mean (SD) EDQ score of the 42 participants who showed no symptoms of exercise dependence or disordered exercising was 100.8 (23.46). A previous study using the EDQ adopted a cut off point for exercise dependence of $\geqslant 116,{ }^{11}$ the equivalent of scoring 4 on average on each of the 29 items. Table 4 indicates the accuracy of this criterion in discriminating those identified as exercise dependent, using the present diagnostic criteria. In addition, it

Table 4 Number of exercise dependent or non-exercise dependent participants as defined by diagnostic criteria and exercise dependence questionnaire (EDQ) score

\begin{tabular}{cll}
\hline & \multicolumn{2}{l}{ Diagnosis } \\
\cline { 2 - 3 } & $\begin{array}{l}\text { Exercise } \\
\text { dependent }\end{array}$ & $\begin{array}{l}\text { Non-exercise } \\
\text { dependent* }\end{array}$ \\
\hline EDQ score & & \\
$\geqslant 116$ & 9 & 14 \\
$<116$ & 1 & 32 \\
$\geqslant 130$ & 6 & 3 \\
$<130$ & 4 & 43 \\
$\geqslant 145$ & 3 & 0 \\
$<145$ & 7 & 46 \\
\hline
\end{tabular}

*Includes four participants who showed symptoms of disordered exercising but did not meet the criteria for exercise dependence. 
indicates the consequences of adopting higher EDQ cut off points. As can be seen, the $\geqslant 116$ cut off point identified $90 \%$ of those diagnosed as exercise dependent, but at some cost in terms of false positives. Thirty per cent of those not regarded as exercise dependent met this cut off point. In contrast, the more severe criterion of $\geqslant 145$, the equivalent of scoring 5 on average on each of the 29 items, yielded no false positives but a high number of false negatives as it captured only $30 \%$ of those judged to be exercise dependent using the diagnostic criteria derived from the narratives.

\section{DISCUSSION}

This study represents the first systematic qualitative study of exercise dependence. Using semistructured interviews and an approach based on a social constructionist version of grounded theory, we analysed the narratives of 56 female exercisers with a view to extracting cogent diagnostic criteria for exercise dependence. In general, the themes that emerged are broadly in line with the diagnostic criteria proposed by Veale $^{48}$ (table 1). The major diagnostic criteria identified in the present study were impaired functioning and withdrawal.

\section{Impaired functioning}

There was evidence of impaired functioning in four areas: psychological, social and occupational, physical, and behavioural. Evidence of problems in at least two of these areas was judged necessary for a diagnosis of exercise dependence; only one would risk overinclusion, whereas insisting on three or more was considered to be overly exclusive. The inability to concentrate because of a preoccupation with exercise and exercise induced fatigue were examples of impaired psychological functioning. Medically contraindicated exercising and arguments with partner, family, or friends, rather than being discrete associated features as proposed by Veale, ${ }^{8}$ were deemed examples of impaired physical and social functioning respectively. For Meg, her exercise behaviour appeared to serve an almost self harming function, "I sometimes push myself and when I am doing that I know it's because I am bad, because I have done something that I shouldn't have." Many participants described conflict between their exercising and other aspects of their lives. For example, Martine, a middle distance runner explained:

"I always fit my exercise in no matter what, even if it means not doing something else like going out or making myself late for something, because I have got to do my exercise. I am always late for work, terrible, like the other day I was out on my bike and I was just like, 'You have got to be at work in an hour, you have got so much to do', and I am like, 'well, I will finish my bike ride so its tough, they will have to wait' . . .it's just something that takes priority over other things."

Clearly, Martine's exercising was creating problems for her work.

Attaching a high priority to sport and exercise is not necessarily problematic. The degree of conflict and its context is important. Indeed, it was not unusual for competitive athletes in the present study to indicate some disruption of other activities as a result of their training commitments. Nevertheless, they were generally able to manage successfully sporting and other demands. Exercise only appeared to impair function when it became all consuming. For Annie, for example, exercising was her only priority. It was detrimental to her social life, her career, and her health. She was clearly distressed by her investment in exercise, "I feel it's a great bind, I feel it rules my life and I don't see why I should have to carry this cross when nobody else does."

\section{Withdrawal}

This diagnostic criterion was manifested as either a clinically significant adverse response to not exercising or as a persistent desire and/or inability to control or cut back on exercise; the latter sometimes presented as a premature return to exercising after illness or injury. Given that mild withdrawal symptoms are common among athletes, only severe instances of withdrawal should be regarded as symptomatic. As truly dependent exercisers would be unlikely to abstain from exercise for research, diagnostic, or even medical reasons, withdrawal symptoms are difficult to assess. In this study, this problem was addressed by asking participants to respond to the hypothetical situation of not being able to exercise for one week. This tactic yielded important data. For example, Jenny was visibly horrified at the prospect and stated:

\section{"You wouldn't, you just couldn't do it, well that's what I feel like ... you are just depriving me of something that is essential to me ... you might as well say, 'stop eating' or 'stop breathing' . . . I should be really depressed, I should be suicidal . . . l just wouldn't be able to cope with just sitting in here . . .without exercising . . you would probably have to put me in hospital."}

Accordingly, use of such hypothetical questions is recommended in the assessment of exercise dependence. For diagnosis of exercise dependence, it was considered that individuals should display at least one but not necessarily both of the two possible manifestations of withdrawal.

\section{Associated features}

A number of additional themes emerged from analysis of the present narratives. However, for reasons explained below, these should, at best, be regarded as indicative rather than definitive of exercise dependence. The present findings support Veale's recommendation that tolerance be abandoned as a criterion for the diagnosis of exercise dependence. ${ }^{28}$ The concept of tolerance is a pharmacological one and unlikely to be generally applicable to exercise. Very few of the present participants reported that increasing exercise loads was a function of compulsion and diminishing subjective benefits, although Joan feared, "If I start doing the exercising . . .I will start doing more and more of it". In most cases, though, it was difficult to attribute increasing schedules of exercise to tolerance. For some, it was clearly a function of a standard incremental athletic training programme. For others, increased exercise was associated with a desire to lose more weight. Although intentionally increasing exercise levels was a common practice, tolerance cannot be inferred from this behaviour. Accordingly, tolerance was not included as a diagnostic criterion. Nevertheless, occasional declarations of a subjective need for increasing amounts of exercise were considered useful pointers and so tolerance was more properly regarded as an associated feature.

A key finding in the present study was the importance of cognitions, such as ruminations about, or inflexible attitudes towards, exercising, as signifiers of exercise dependence. In contrast, frequency, duration, or overall volume of exercise undertaken did not differentiate unambiguously dependent and non-dependent exercisers. Bamber and colleagues ${ }^{11}$ also found no relation between exercise dependence and exercise volume. As such, diagnostic criteria based solely on amounts of exercise would appear to be inadequate. For example, Alison, a triathlete, who was clearly not exercise dependent, reported training seven days a week, often twice daily. On the other hand, analysis of negative cases ${ }^{27}$ raised the possibility that exercise dependence could occur at relatively low levels of exercising. For example, Meg insisted on climbing up and down the bottom stair for five minutes every morning and 
would be in "a bad temper" if she overslept and missed doing it. Similarly, Rebecca felt unable to tolerate not doing her five to ten minutes of daily weight training and sit ups:

"If I get to the end of the day and I think, 'Oh God I haven't done my exercises' I do feel agitated and I have even got out of bed to do them ... its just this overwhelming sensation really that I have to do them, even though I am tired and I just want to go to sleep."

What would seem to be a behavioural discriminator in this context is the stereotyped and rigid character of the exercise. Irrespective of volume, some of the present participants exhibited an inflexible pattern of behaviour that was self imposed. Meg and Rebecca provide striking examples. In contrast with volume, then, rigidity was considered a diagnostic criterion, an example of impaired behavioural functioning.

Veale $^{8}$ included a subjective awareness of exercising as a problem in his diagnostic criteria. In the present study, insight was explored by asking participants if they felt their exercising was problematic, excessive, or an addiction. Their subjective definitions of exercise dependence were also explored. Our analysis indicated that some potentially dependent exercisers denied that exercising was a problem. This is illustrated by the following extract from a theoretical memo stored in NUDIST:

\begin{abstract}
"When coding Roxanne it occurred to me that some individuals have greater or lesser insight into their exercise dependence. For example, Roxanne defined exercise addiction as, 'exercising 7 days a week, 2-3 hours a day, and feeling upset if unable to exercise'. She had described that pattern of behaviour and withdrawal in herself, but when I asked if she felt she was addicted to exercise, she still said, 'No'. It seems she is denying her dependence." (DB)
\end{abstract}

Lack of subjective awareness can be variously manifest as secretive exercising, lying about exercising, and denial of exercising as a problem. In this study, the probe question, "Would other people say that you exercise excessively?" elicited such responses as, "Only the lazy ones in this world". Martine's housemates clearly thought her exercising was excessive, as she recounted their comments, "You are just mad, you go on these futile runs all the time, you know, what's going on? ... Martine's going on one of her runs around the world." Martine insisted that she did not have a problem. Interviews with significant others could be valuable to future exercise dependence research. In general, given that many potentially dependent participants were very resistant to any implication that their exercising was problematic or pathological, insight, as a diagnostic criterion, would result in substantial false negatives.

\section{Diagnosis of primary and secondary exercise dependence}

Ten of the participants in this study met our new diagnostic criteria for exercise dependence. It is worth noting that their scores on the EDQ were significantly higher than individuals not meeting the criteria. Further, a cut off point on the EDQ of $\geqslant 116$, in contrast with more stringent EDQ cut off points, captured nine of the 10, although at the cost of a number of false positives. Those who did not meet fully the present diagnostic criteria, and were characterised as disordered exercisers, were not significantly different from non-dependent exercisers on the EDQ. This result could be taken as indicating that diagnosis using the present scheme should be restricted to those who unambiguously meet the criteria for exercise dependence, although it may also reflect the insensitivity of the EDQ. Identifying disordered exercising could be impor- tant. Early identification of those at risk-that is, individuals who are not as yet exercise dependent but show many of the characteristics-may help to prevent the development of exercise dependence. Further, it is important to recognise that the EDQ is not a diagnostic instrument; diagnosis should proceed on the basis of interviews of the sort conducted in this study.

Veale $^{4}$ has argued that, for exercise dependence to be deemed a primary pathology, it should be independent of any other clinical disorder, particularly an eating disorder. In the present study, impaired functioning and withdrawal were considered likely to characterise both primary and secondary exercise dependence, differentiation being based on the absence or presence of an eating disorder. All 10 exercise dependent women in this study showed evidence of an eating disorder. Thus, all 10 fulfilled the criteria for secondary, rather than primary, exercise dependence. This is in line with the results of a recent study, ${ }^{11}$ which concluded that, if primary exercise dependence exists in women, it is a rare phenomenon, and does not have anything like the prevalence rates reported in some previous studies. ${ }^{29}{ }^{30}$ The present results reinforce the importance of systematically screening for eating disorders when studying exercise dependence.

It is worth noting, though, that dieting for performance was not typical of those participants meeting the criteria for secondary exercise dependence. Veale ${ }^{8}$ proposed that dieting for performance represented an associated feature of secondary exercise dependence. Although it is difficult to distinguish between dieting as a symptom of an eating disorder and dieting for performance, particularly in weight dependent or aesthetic sports, the present data do not support Veale's proposal. Participants who met the criteria for secondary exercise dependence dieted predominantly to control weight, shape, or body composition rather than to improve athletic performance.

It is important to remember that no women in this study showed evidence of primary exercise dependence. Accordingly, the proposed criteria for primary exercise dependence remain speculative. Indeed, it would seem advisable to extend the proposed criterion for primary exercise dependence, relating to the absence of an eating disorder, to exclude exercise that can be better explained by any other psychiatric disorder. For example, obsessive-compulsive disorder may be manifested as apparent "dependent" exercising. Future attempts to identify primary exercise dependence need to include a full psychiatric assessment to rule out excessive exercising as an associated feature of any other disorder. It remains possible that primary exercise dependence does not exist as a primary clinical disorder.

From these data it is impossible to determine whether the secondary exercise dependence diagnosed is a secondary feature of an eating disorder or a true co-morbidity. However, the concept of secondary exercise dependence implies cause and effect. Given that the cause of exercise dependence and its precise relation to eating disorders remain to be determined, it may be more appropriate to adopt the term "associated exercise dependence", which continues to allow the possibility of genuine co-morbidity. After all, not everyone who exhibited an eating disorder in this study was exercise dependent. Indeed, for some with eating disorders, exercise may have an ameliorative effect. A number of participants reported that exercise encouraged them to eat more healthily and made them less likely to binge. It remains to be established why certain eating disorder sufferers show the symptoms of exercise dependence whereas others do not.

There could be important sex differences in the manifestation of exercise dependence. Primary exercise dependence may be more common among men, because eating disorders are known to occur much more often in women than men. The selection of women for these analyses maximised the opportunity to examine the complex relation between eating 


\section{Take home message}

- Diagnostic criteria for exercise dependence in women have been derived from systematic qualitative analysis

- The search for primary exercise dependence continues

- There my be sex differences in the manifestation of exercise dependence

disorders and exercise. It is possible that our sampling procedures are responsible for the apparent non-existence of primary exercise dependence: the most "dependent" exercisers may have been unwilling to volunteer their time.

We recommend that these new diagnostic criteria be adopted in favour of earlier criteria for exercise dependence. Clinicians and researchers are invited to test them out in practice and to offer feedback about their replicability among men. Should any evidence for primary exercise dependence emerge, then more definitive diagnostic criteria can be developed.

\section{Authors' affiliations}

D J Bamber, University of Cambridge, UK

I M Cockerill, D Carroll, University of Birmingham, UK

S Rodgers, Rotherham General Hospital, UK

\section{REFERENCES}

1 Brewerton TD, Stellefson EJ, Hibbs N, et al. Comparison of eating disorder patients with and without compulsive exercising. Int J Eat Disord 1995;17:413-16.

2 Davis C, Kennedy SH, Ralevski E, et al. Obsessive compulsiveness and physical activity in anorexia nervosa and high level exercising. J Psychosom Res 1995;39:967-76.

3 Touyz SW, Beumont PJV, Hook S. Exercise anorexia: a new dimension in anorexia nervosa? In: Beaumont PJV, Burrows GD, Casper RC, eds. Handbook of eating disorders, part 1 Amsterdam: Elsevier Science Publishers, 1987: 143-57.

4 Veale D. Does primary exercise dependence really exist? In: Annett J, Cripps B, Steinberg H, eds. Proceedings of Warwick University workshop: exercise addiction: motivation for participation in sport and exercise. Leicester: The British Psychological Society, 1995: 1-5.

5 Anshel MH. A psycho-behavioural analysis of addicted versus non-addicted male and female exercisers. Journal of Sport Behaviour 1992;14:145-59.

6 Ogles BM, Masters KS, Richardson SA. Obligatory running and gender: an analysis of participative motives and training habits. Int J Sport Psychol 1995;26:233-48.

7 Morgan WP. Negative addiction in runners. Physician and Sports Medicine 1979;7:57-70

8 Veale DMW. Exercise dependence. Br J Addict 1987;82:735-40.
9 Ogden J, Veale D, Summers Z. The Development and validation of the exercise dependence questionnaire. Addiction Research 1997;5:343-56.

10 Blumenthal JA, O'Toole LC, Chang JL. Is running an analogue of anorexia? An empirical study of obligatory running and anorexia nervosa. JAMA 1984;252:520-3.

11 Bamber D, Cockerill IM, Carroll D. The pathological status of exercise dependence. Br J Sports Med 2000;34:125-32.

12 Blaszczynski AP, Buhrich N, McConaghy N. Pathological gamblers, heroin addicts and control compared on the EPQ "Addiction Scale". $\mathrm{Br}$ Addict 1985;80:315-19.

13 Carroll D, Huxley JAA. Cognitive, dispositional, and psychophysiological correlates of dependent slot machine gambling in young people. J Appl Soc Psychol 1994;24:1070-83.

14 Gossop MR, Eysenck SBG. A further investigation into the personality of drug addicts in treatment. BrJ Addict 1980;75:305-11.

15 Fairburn CG, Beglin SJ. Assessment of eating disorders: interview or self-report questionnaire? Int J Eat Disord 1994;16:363-70.

16 American Psychiatric Association. Diagnostic and statistical manual of mental disorders. 4th ed. Washington DC: American Psychiatric Association, 1994.

17 Cripps B. Exercise addiction and chronic fatigue syndrome: case study of a mountain biker. In: Annett J, Cripps B, Steinberg H, eds. Proceedings of Warwick University workshop: exercise addiction: motivation for participation in sport and exercise. Leicester: The British Psychological Society, 1995:22-33.

18 Griffiths M. Exercise addiction: a case study. Addiction Research 1997;5:161-8.

19 Sachs ML, Pargman D. Running addiction: a depth interview examination. Journal of Sport Behaviour 1979: 143-55.

20 Seheult C. Hooked on the "buzz": history of a bodybuilding addict. In: Annett J, Cripps B, Steinberg H, eds. Proceedings of Warwick University workshop: exercise addiction: motivation for participation in sport and exercise. Leicester: The British Psychological Society, 1995:40-44.

21 Charmaz K."Discovering" chronic illness: using grounded theory. Soc Sci Med 1990:30:1161-72.

22 Henwood K, Pidgeon N. Grounded theory and psychological research. The Psychologist 1995 Mar: 115-18.

23 Jackson AS, Pollock ML. Practical assessment of body composition. Physician and Sports Medicine 1985:13:76-90.

24 Fairburn CG, Cooper Z. The eating disorder examination. 12th ed. In: Fairburn CG, Wilson GT, eds. Binge eating: nature, assessment and treatment. New York: Guilford Press, 1993:317-60.

25 Miles MB, Huberman AM. Qualitative data analysis. London: Sage, 1994.

26 Qualitative Solutions and Research Pty Ltd. QSR NUD*IST 4 user guide. 2nd ed. London: Sage, 1997.

27 Strauss A, Corbin J. Basics of qualitative research: grounded theory procedures and techniques. London: Sage, 1990.

28 Veale DMW. Psychological aspects of staleness and dependence on exercise. Int J Sports Med 1991;12:S19-22.

29 Anderson SJ, Basson CJ, Geils C. Personality style and mood states associated with a negative addiction to running. Sports Med 1997:4:6-11

30 Slay HA, Hayaki J, Napolitano MA, et al. Motivations for running and eating attitudes in obligatory versus nonobligatory runners. Int J Eat Disord 1998;23:267-75. 